\title{
Consciousness and Conscience: Feminism, Pragmatism, and the Potential for Radical Change
}

\author{
CLARA FISCHER ${ }^{1}$ \\ Irish School of Ecumenics, Trinity College Dublin, Dublin, Ireland
}

\begin{abstract}
Pragmatist philosopher John Dewey famously stated that man is a creature of habit, and not of reason or instinct. In this paper, I will assess Dewey's explication of the habituated self and the potential it holds for radical transformative processes. In particular, I will examine the process of coming to feminist consciousness and will show that a feministpragmatist reading of change can accommodate a view of the self as responsible agent. Following the elucidation of the changing self, I will appraise key pragmatist concepts of inquiry, such as doubt and self-reflexivity, with regard to their treatment of deep-seated internalizations of oppressive norms and the initiation of change. Ultimately, I will argue that a feminist-pragmatist understanding of transformation is conducive not only to the project of personal transformation, but also to social and political change more generally.
\end{abstract}

\section{Introduction}

As societies are generally characterized by power differentials between varioussometimes overlapping - groups, demands for social justice fundamentally constitute demands for an abolition, or at least a diminishing, of such power disparities. Social movements, however, often appear incapable of carrying out the perhaps more radical visions of change they promise and thus fall short of fulfilling said demands for social justice. For example, despite the sustained activism of women, gender equality remains a formality in many countries, with men still in control of the majority of the world's economic and political resources. It is because of this that many feminists have come to theorize the possibility of radical change not merely in terms of institutions and political structures, but in terms of something much more drastic: we, our very selves, need to change.

Building upon this insight, I will explore the power of personal transformation in bringing about systemic social change. In this way, I hope to undo the limitations placed upon a potentially liberatory understanding of social justice by a too-narrow preoccupation with large-scale institutions and systems. For example, first-wave feminism's focus on suffrage and democracy as a vehicle for the realization of social 
justice has been shown to be only partially successful, particularly as women's political representation failed to soar and instead flattened out in many countries in the early decades of the twentieth century. While political structures are of course pertinent in the context of social justice, we should also pay considerable attention to the workings of our individual consciousnesses, and the kind of selves we are.

But what exactly is the self? How do we change our selves? And what is the connection between a changed self and its environment? This paper will try to answer these questions and will draw attention to the role knowledge plays in relation to radical transformative processes. Such processes usually require a rethinking of oppressive norms and values that are portrayed as unproblematic and natural. Hence, alternative knowledges and altered understandings have a central role to play in undermining oppressive systems.

Specifically, this paper will draw upon the work of John Dewey in order to establish a feminist-pragmatist analysis of change, which will be explored via the radical transformative process of coming to feminist consciousness. Insights gained from such an analysis at the level of the self will then be extrapolated onto the broader institutional level. Additionally, Dewey's melioristic worldview will be discussed and the question of a democratically devised notion of progress broached. Throughout, I will keep in mind such questions as the following: Is personal change possible? What causes personal change? What is the role of knowledge in changing oneself? What implications does changing ourselves have for us as moral beings? I will begin by outlining the relationship between self, agency, and moral responsibility, and the possibility of personal change from a feminist perspective.

\section{Morality, Agency, and the Possibility of Change}

In her essay "Moral Responsibility and Social Change: A New Theory of Self," feminist philosopher Ann Ferguson (1997) outlines what she calls the "determinismresponsibility problem” (p. 117). This consists of the following predicament: How can systems of oppression be dismantled, or at least to some extent changed, if people's agency is overly deterministic? In other words, in order to be held morally accountable for changing systems of oppression, oppressor and oppressed need to be theorized as being capable of carrying out such change in the first place. Indeed, to

avoid this [determinism-responsibility] problem, any explanation of how systems of domination are supported by dominators and submitted to by subordinates must avoid being deterministic in a way that implies that both those who benefit and those who are oppressed are not morally responsible for challenging and resisting those systems. (p. 117)

Ferguson explores various feminist theories which aim to explain systems of oppression, but finds each of these incapable of solving the determinismresponsibility problem.

For example, radical feminism's essentialism (women as naturally caring, loving, and good vs. men as aggressive, cold, or calculating) does not allow for a change in these supposed intrinsic natures. Social constructionist theories, on the other hand, while defying a view of fundamental inalterable male and female natures, 
overemphasize the role of socially created structures of selfhood. Thus, as "both dominators and dominated are made to collude in sexist practices through the force of internalized desires and constructions of self" (p. 119), these theories "so overstate the determinism involved as to make it unclear how anyone could ever escape racist self-concepts or heteropatriarchal desires" (p. 120). Liberal feminist theory "rules out psychological theories that posit social oppression as creating a 'deformed' or 'truncated self'”' (p. 120), as liberalism's rational individual operates purely in terms of costs and benefits accrued in social situations. ${ }^{2}$ Finally, poststructuralist theory initially appears to escape over-determinism, as it views the self in constant flux. And yet, "such a self-process must have some relatively stable elements in order even to take on the goal of changing," including "a sense of a unique history, set in social relationships with specific others, and habitual responses tied to a particular body through both memory and aspiration” (p. 121). As Ferguson demonstrates, all of these major feminist theories-radical, social constructionist, liberal and poststructuralist - have major shortcomings in that they portray selves as either too deterministic or too transient. This in turn prohibits them from positing a self that is capable of changing.

While Ferguson goes on to outline her "social materialist, decentred theory of subjectivity" (p. 116) as an alternative capable of overcoming the determinismresponsibility problem, I contend that John Dewey's view of the self can also be appropriated by feminists to do precisely that. Dewey provides us with an explication of the self, which accommodates both a permanent, connected, and coherent self, on the one hand, and a flexible, dynamic self, on the other. Thus, Dewey's theory of subjectivity represents a third option to those overly deterministic visions of the self, and those transient, overly fluid interpretations of the self, both of which render change, and hence moral responsibility, impotent. It is in this sense then, that the Deweyan view of selfhood can make change an ethically valuable concept, drawing attention to the moral responsibility we each have as agents in the transformation of oppressive systems.

\title{
Dewey's Self
}

For Dewey, the self is a corporeal, socially embedded being, ${ }^{3}$ composed of a unique set of habits. Habits are socially acquired responses, ${ }^{4}$ which we come to amass over the course of a lifetime-a process enabled through our capacity to learn. Thus, according to Dewey (1985b),

\begin{abstract}
Habit is the mainspring of human action, and habits are formed for the most part under the influence of the customs of a group. The organic structure of man entails the formation of habit, for, whether we wish it or not, whether we are aware of it or not, every act effects a modification of attitude and set which directs future behaviour. (p. 334)
\end{abstract}

This future-directed interpretation of habit is also morally significant, as we learn to identify good and bad acts and dispositions. ${ }^{5}$ Hence, in the case of a misbehaving child, for example, the adults of a group tend to correct the child so it knows which way to act in future. Dewey writes: 
The child . . . is at first held liable for what he has done, not because he deliberately and knowingly intended such action, but in order that in the future he may take into account bearings and consequences which he has failed to consider in what he has done. (1985a, p. 303)

Although this socially learned process of habit acquisition may imply uniformity and conservatism, our particular set of habits actually makes us unique, as nobody's experiences, and hence nobody's responses, will be absolutely identical. As Gouinlock (1972) notes:

Each individual possesses a fund of habits distinguishable from that of others. The fact that habits function together, and in ways distinctive of a particular individual, accounts for the fact of "character" - of a more or less unified and dynamic composite of personality traits. This, indeed, is what Dewey means by the self: a dynamic organization of habits. (p. 95)

Dewey believes that there is a tendency in adults to submit to stale and inflexible habits, while younger people are still more adaptable and open to different ways of thinking and acting. However, this does not mean that an adult cannot change her habits (1985a, p. 305). In fact, according to Dewey, we need to constantly reassess our habits, particularly as the world is an evolving place, where old habits may no longer be suitable to novel conditions. Dewey's organic view of the world thus posits a self which is stable, but which is also constantly changing, and which we should enable to change according to its environment. As we can see, Dewey does not view the person as separated, but as embedded and influenced by the world around her. Hence, every act we undertake will have an effect on the world (and vice versa), including on our own self. As Dewey (1985a) explains:

Except as the outcome of arrested development, there is no such thing as a fixed, ready-made, finished self. Every living self causes acts and is itself caused in return by what it does. All voluntary action is a remaking of self, since it creates new desires, instigates to new modes of endeavour, brings to light new conditions which institute new ends. Our personal identity is found in the thread of continuous development which binds together these changes. (p. 306)

Here we have the fluidity of selfhood which is so common of poststructuralist theory. Yet at the same time, this transient, changing view of the self is complemented by a stable and enduring structure of personal identity. The dual aspect of Deweyan selfhood is aptly described by him as containing a "distinction between an old, an accomplished self, and a new and moving self, between the static and the dynamic self” (p. 305). As he outlines,

The former aspect is constituted by habits already formed. Habit gives facility, and there is always a tendency to rest on our oars, to fall back on what we have already achieved . . . Hence, the old, the habitual self, is likely to be treated as if it were the self; ... . We become uneasy at the idea of initiating new courses; we are repelled by the difficulties that attend entering upon them; we dodge assuming a new responsibility. We tend to 
favour the old self and to make its perpetuation the standard of our valuations and the end of our conduct. In this way, we withdraw from actual conditions and their requirements and opportunities; we contract and harden the self. (p. 306)

And yet, "the growing, enlarging, liberated self . . . goes forth to meet new demands and occasions, and readapts and remakes itself in the process. It welcomes untried situations" (p. 307). For Dewey, we are constantly faced with a choice between acting in accordance with the old, static self, or with the new, dynamic self.

We should not, however, think of these two selves as ontologically separate, but rather as coexistent and interwoven aspects of a single self, which is both constant and changing at the same time. Hence, Dewey's depiction of a stable-yet-dynamic self serves to highlight the nature of the self as a fund of habits which is always moving, but which also contains a permanent structure. Habits are the unique ways in which we interact with the world, but they also constitute the building blocks of our very character. Dewey makes the point by drawing an analogy with a house (1988, p. 64). We can imagine that a house may be run down in certain parts (with drain pipes leaking in the bathroom, and damp developing on an outside wall), while other parts may display entirely new features (a new extension), and yet others showing signs of repairs (replacement windows for example).

Similarly, the structure of my self is provided by the structure of the house, and just as certain habits of mine have fallen into disrepair and become abandoned, others are either completely new or have been refreshed and updated. Now, as we have noted, the self is constructed through habit by its interactions with its environment, and vice versa. In the context of my own life, ${ }^{6}$ then, we can say that my being born into a musical family meant that my character and the habits making up my character were informed by this musical environment and helped to shape myself as a musical self. For example, I acquired a habit of piano playing, which for a long time was a central part of my self, with many hours of practice strengthening this habit. Unfortunately moving out of the family home several years later meant that I no longer had access to a piano and hence the habit of playing the piano, like the drain pipe or the damp wall in our analogy of the house, was gradually neglected. Recently, however, the gift of my mother's old piano rekindled and strengthened the formerly abandoned habit of piano playing, which now again forms an important part of my self.

This change in habit becomes interesting when we note how complex the self really is. Piano playing is just one of many, many habits making up my self, and the processes habits undergo-whether they remain static, become replaced by other habits, or get recycled into yet others-are multifarious and often overlapping. I mean overlapping here in two senses: changes in habit can occur at different speeds; in addition, they may necessitate further changes, as certain habits depend upon other habits. Dewey (1988) characterizes the former, temporal aspect of change in habits by noting that the structure of a house forms "an arrangement of changing events such that properties which change slowly, limit and direct a series of quick changes and give them an order which they do not otherwise possess" (p. 65). In other words, the stability provided by the structure composed of habits enables changes to take place at different speeds, and provides the framework in which change can take place coherently against a backdrop of the past and potentiality of the future. Also, as we 
will see more clearly in the next section, it is precisely because habits are part of a structure that the removal or introduction of a particular habit can have a knock-on effect on other habits. For example, since my habit of piano playing has been restored, I now find myself increasingly on the look-out for sheet music. Hence, I have acquired a new habit of purchasing and borrowing sheet music. The money needed to engage in this new habit has been directed away from other habits, hence the habit of buying coffee twice a week after work has now been met with the same fate piano playing once encountered after my move out of the family home.

But how does this relate to the moral questions we raised at the beginning? Recalling that Dewey's division of self into dynamic and stable is merely a functional division, aimed at clarifying the structure/change accommodation of the self as a fund of habits, we can assert that Dewey places particular emphasis on the dynamic aspect of the self. For Dewey (1985a), the latter implies not only progress, but moral progress. He writes:

For everywhere there is an opportunity and a need to go beyond what one
has been, beyond "himself," if the self is identified with the body of
desires, affections, and habits, which has been potent in the past. Indeed,
we may say that the good person is precisely the one who is most
conscious of the alternative, and is the most concerned to find openings
for the newly forming or growing self; since no matter how "good" he has
been, he becomes "bad" . . . as soon as he fails to respond to the demand
for growth. Any other basis for judging the moral status of the self is
conventional. In reality, direction of movement, not the plane of
attainment and rest, determines moral quality. (p. 307)

Indeed, for Dewey, the ethical person cultivates a habit of openness which enables her to remain flexible and to question the dependability of other, perhaps rather outdated, habits. Such self-reflexivity is fostered through intelligent inquiry, and constitutes growth, a process which is morally significant, as morality is held to be movement, rather than the attainment of static ends. ${ }^{7}$ Having said all this, we can see that Dewey's habituated dynamic-permanent self constitutes an alternative to both unduly deterministic theories of subjectivity and poststructuralist theories, thereby overcoming the determinism-responsibility problem by allowing for a self that is capable of change. Dewey also places the burden for change squarely into the hands of every agent, reinforcing the view that a refusal to welcome change is not only outmoded or inappropriate, but that it is immoral. From a feminist point of view, this is, of course, utterly appealing, as Dewey's theory of selfhood can explain agency, thus rendering personal, as well as large-scale, social transformation possible. Since people are shown to possess the capacity to resist or subvert oppressive systems, they can be held morally accountable for failing to do so. ${ }^{8}$

\section{Feminist Consciousness}

The process of coming to feminist consciousness is perhaps one of the most lifealtering events a person is likely to experience, as it initiates not only a radical rethinking of one's existence as such, but it usually also acts as a catalyst to changes 
stretching far beyond one's personal experience of self. Indeed, the changes we undergo in understanding ourselves, the relationships we have with other people, institutions and the world as such, appear to be so radical, that coming to feminist consciousness is frequently described in epiphanous terms, as an "aha moment" or a sudden enlightenment. Outlining her entry into the early women's liberation movement, Lynne Segal (2007), for example, recalls her own experience of coming to feminist consciousness and the intense feeling of personal change as follows:

That sense of being lost, lonely and bewildered, the condition I thought I had brought upon myself in fleeing respectability, turned out to be far from unusual . . . Why were so many of us quite so confused? . . . We were educated to be happy, healthy, thinking people, and more was invested in and expected of us than ever before. But many sensed the cloud behind that silver lining, suspecting that our growth and fulfilment was not compatible with the image of femininity thrust before us . . . The narratives that would address our needs and confusions, . . . seemed to operate like a spiritual renewal: "Women's liberation suddenly lifted the curtain concealing the big world from us ...." I too experienced exactly those moments of sudden awakening. (pp. $64-67$ )

This experience of moving from a state of confusion to sudden awakening is something that is frequently attested by feminists. ${ }^{9}$ While Segal's experience will reflect the Zeitgeist of the time, the "conversion" process itself is something many women describe in remarkably similar terms. Thus, even though the once popular feminist consciousness raising groups seem to have disappeared in the West, and even though women's status and social roles have undergone considerable changes since those early Women's Liberation days, the actual experience of encountering and identifying with feminism for the first time appears to be as epiphanous and enlightening as ever. This certainly holds true for my own feminist conversion, which took place in a very different setting, and which rebelled against a different paradigm of femininity nearly forty years after Segal's moment of awakening.

But what can Dewey tell us about this personal, very radical, life-altering experience? Indeed, radical is perhaps the best word to describe it, as with hindsight it seems that my life can be split into a pre-feminist, unenlightened phase, and a postconversion, feminist phase, with two completely different selves acting under the guise of "me." But is this possible? Is the separation of pre-feminist self from a feminist self feasible? If we take on board Dewey's insights with regard to a stable yet dynamic self, we know that this cannot be so. Recalling Dewey's analogy of the house, we know that change takes place non-uniformly and at varying speeds, but also against the back-drop of a structure provided by the house. Hence, feminist consciousness must have changed certain habits which formed part of my self, but it did not erase all of my habits prior to the conversion experience. As Sullivan (2000) notes:

Release from all structures of identity—if such a thing were possiblewould not free us . . . to be whatever we want. Rather, it would dissolve us into beings with no capacity for or agency to effect transformation and change, effectively eliminating—not increasing—our freedom. (p. 29) 
The complete annihilation of a pre-feminist self would simply not allow for a rebuilding of a new, feminist self, for who would do the building? Feminist consciousness has allowed me to discard some habits, which I've deemed to be patriarchal in origin, while retaining other habits, and acquiring yet others-all of which collectively make up my character.

As we've noted, changes of habit take place according to varying tempos, impacting on other habits in non-uniform ways. Feminist accounts of coming to feminist consciousness as a truly radical experience confirm this interdependent nature of our habits. Indeed, it appears that once one has become "converted" or "enlightened," feminism and feminist analyses seem to permeate large swathes of one's life. So norms surrounding sexuality, body-image, personal relationships, career paths, and so on, are all re-evaluated with old, patriarchal habits being dropped (to varying degrees and at varying speeds), making space for newly developed habits. It is for this reason that theorists often speak of viewing the world with gendered or feminist lenses.

To clarify further, let me illustrate the point. Feminist accounts of coming to feminist consciousness attest to a personal transformative process, which begins with perplexity and uncertainty, and reaches a state of greater clarity (hence the "aha" sensation), aided by a new feminist understanding of one's self. Habits are gained, rejected, or reused, as they are interpreted as either patriarchal or not. For example, several women philosophers have noted their reluctance in calling themselves philosophers. ${ }^{10}$ Coming to feminist consciousness can allow women philosophers to gain an awareness of this, to analyze its causes, and to try to undo this tendency. The habit of referring to oneself subordinately as a "teacher of philosophy" or a "person in philosophy" can thus be abandoned, and replaced by a new habit directly asserting "I am a philosopher." The impact this can have on one's character is tremendous, as habits interact with other habits to form the dynamic-yet-stable self.

All of this, of course, requires a high level of reinterpretation of previous experiences, and a high level of self-reflexivity. As feminists have shown, patriarchy can work very subtly, and as social constructionists in particular have pointed out, our very desires, hopes, and aspirations may be informed by internalized sexism. And yet, recalling the discussion of the previous section, we should be wary of falling back into an over-determinism which completely denies our agency. Indeed, "Dewey's somewhat paradoxical-sounding advice that we need to form the habit of not forming fixed habits” (Sullivan, 2000, p. 39) can help us to be more selfreflexive. But is such self-reflexivity enough to counter unconscious sexist norms? Considering the rigorous socialization processes we undergo from a very young age, can a habit of openness and questioning undermine such gendered internalizations? Could this, in turn, diminish Dewey's capacity to overcome the determinismresponsibility problem? Have we been too hasty in designating Dewey's view of a self composed of habits as the solution to this problem?

Let us briefly return then, to what Dewey (2002) has to say about the habituated self and the potential for change. Habits are capable of providing structure, precisely because they resist change to a certain extent. Hence, Dewey asserts that:

the trouble lies in the inertness of established habit. No matter how accidental and irrational the circumstances of its origin, no matter how

Studies in Social Justice, Volume 4, Issue 1, 2010 
different are the conditions which now exist from those under which the habit was formed, the latter persists until the environment obstinately rejects it. (p. 125)

This, for Dewey creates a "vicious circle" (p. 126) in which our selves are composites of socially acquired habits, but where changes to those habits are rendered nigh on impossible. To counter this, Dewey recommends the fostering of self-reflexivity, preferably from a very early age when our habits are still more malleable, hence the importance of education in Dewey's philosophy. However, there is another route out of the "vicious circle." Our habits, according to Dewey, are often contradictory and in tension with each other. In moments of heightened tension and friction we encounter the real possibility of change as the seeming harmonious functioning of our habits ceases to be, and we need to discard those well-worn grooves etched by our modes of being and start creating new ones (2002, p. 128). But what happens when we deny or avoid such increased tension? Dewey acknowledges that people often want to revert to old habits to reclaim a sense of stability. However,

\begin{abstract}
laxity due to decadence of old habits cannot be corrected by exhortations to restore old habits in their former rigidity. Even though it were abstractly desirable it is impossible. And it is not desirable because the inflexibility of old habits is precisely the chief cause of their decay and disintegration. Plaintive lamentations at the prevalence of change and abstract appeals for restoration of senile authority are signs of personal feebleness, of inability to cope with change. It is a "defense reaction.” (p. 130)
\end{abstract}

This last sentence is significant, as it indicates that Dewey was aware of our resistance to change. Of course we are often not cognizant of this, particularly when it comes to aspects of our selves which are difficult to deal with. Sullivan (2004) outlines this in relation to racial discrimination and white privilege. She notes that habits "can often be defense mechanisms by which one protects oneself from perceived dangers and conflicts, the protection often including avoidance of conscious self-examination" (p. 200). The language here is remarkably similar to Dewey's, and yet, I think Dewey drastically underestimated the power of such selfsabotaging habits. This is not simply a matter of a lazy reliance on old and trusted habits in spite of novel conditions, but a resistance to changing habits of self which are the result of and the creators of oppressive norms. It is for this reason that Dewey needs to be complemented by feminist theorizing on the creation, functioning, and perpetuation of such norms, and the habits and psychical structures which try to resist their transformation.

While Dewey was certainly aware of women's inferior positioning in society, it is feminist theories, which explicitly take such positioning as a starting point, hence feminism's capacity to illuminate the intricate and often unconscious workings of oppression. Since oppression is often murky and elusive, feminists, like miners, have had to unearth the more or less unquantifiable, the seemingly illusory and the intangible. ${ }^{11}$ The fruits of this digging around in conscious and unconscious gendered existence lie in the prolific analyses of a range of aspects of people's lives-from body image to moral development. By capturing and articulating the specific manifestations of patriarchy and their effects on women and men, feminists 
have been able to tease out not only the intersections and functionings of the more obvious oppressive patriarchal norms, but also of the very habits underpinning these as part of our unconscious selves. Feminist theories are therefore fundamental to an understanding of selves which are both informed by, and instrumental in, the perpetuation of oppressive norms and the systems they uphold. It is only by facing the unconscious, obstructive workings of our habits head-on that our selves can be changed, and the functioning of oppressive norms interrupted. Premised upon this transformation of individual (un)consciousness is the real possibility of wider, systemic change. A feminist-Deweyan analysis of change therefore holds the potential not only for change of the self, but also for change of oppressive systems. But how does such an analysis explain the occurrence of change in habits in the first place? In this regard, Dewey's appreciation of habit as socially acquired response is pertinent.

As we have seen, Dewey (1985a) believes correcting a child is useful not as punishment, but rather as a way for it to understand what has been done wrong in the past, so the mistake can be avoided in the future. The same can be said for an adult, as the

fact that one did not deliberate before the performance of an act which brought injury to others, that he did not mean or intend the act, is of no significance, save as it may throw light upon the kind of response by others which will render him likely to deliberate next time he acts under similar circumstances. (p. 304)

From a feminist point of view, such a reliance on people's responses can be problematic, as in an oppressive system, where sexism is openly or tacitly condoned, a reprimand for sexist actions and attitudes by others is likely not to occur. Similarly, those more subtle, even unconscious, habits discussed above are probably not going to be questioned by many women, nor by the rest of society. We have noted, however, that feminist theories of socialization and the psychology of sexism are capable of shedding light on these phenomena, and it is from these that new habits, and hence new character, emerge. Indeed, the process of coming to feminist consciousness can replace the dominant, oppressive group of social approvers/reprimanders posited by Dewey in the formation of habits, with the discourses and analyses of the oppressed group. In other words, our habits are no longer structured by patriarchal norms, but by feminist ones. Thus, after coming to feminist consciousness, a woman will turn to other feminists for approval, and her actions, beliefs, ideals, etc., will be shaped by their advice, their insights. This will also take place retrospectively, with past experiences now understood within a feminist world-view. ${ }^{12}$ Since we are capable of learning, our new feminist insights and our entry into the feminist community will ensure that other feminists' responses to our actions and thoughts will enable future feminist - rather than sexist-acts. ${ }^{13}$

It is in this sense, also, that motivations resulting from internalized patriarchal norms can be undermined, as feminists have done considerable work on highlighting and capturing these previously unnoticed sexist preconceptions. By drawing upon feminist analyses of the pervasiveness of the values of oppressive systems, Dewey's view of the melioration of acts which were not intended to do harm, but which in fact do contribute to the continuation of oppressive systems, can be asserted. In other 
words, those unintentional, yet harmful, acts (which are plentiful in patriarchal societies where people assume sexist norms often unconsciously) can be countered by adopting Dewey's account of group approval, and embellishing it with feminist theories of socialization and the psychology of sexism. ${ }^{14}$ Thus, feminist insights can undo Dewey's short-sightedness in relation to deep-seated, unconscious oppressive norms, thereby providing a feminist-Deweyan solution to the determinismresponsibility problem. Further, the combination of feminist and Deweyan theory, and its explication of a transformation of habits through group approval and disapproval, is pertinent not only in the scenario of coming to feminist consciousness, but also for the possibility of larger, structural change.

For now, it is important to note that what might be termed the "approvaldisapproval mechanism" and its ethical implications for change on a personal level are instrumental in the creation of a feminist self. This is not to claim that we merely tailor our ethical beliefs and actions to the dominant ideals of the group ${ }^{15}$-a sort of herd mentality-but rather that our social nature plays a vital role in the creation of selves which require a certain sense of community. Thus, McKenna (2002) describes Deweyan individuals as being "formed, though not determined, by their society" (p. 147). On top of this, Dewey (1985a) notes that "being held accountable by others is . . . an important safeguard and directive force in growth” (p. 305). Growth again, being the movement of ethical development, a process of moral improvement, where our new, dynamic, and now feminist self undergoes continuous adaptation, with actions shaping new ideals, in turn creating new aspects of the self, and so on (1985a, p. 306). Thus, "the fact that each act tends to form, through habit, a self which will perform a certain kind of acts, is the foundation, theoretically and practically of responsibility” (p. 304).

\section{Knowledge, Doubt and Change}

But what sparks such a monumental identity shift, such as coming to feminist consciousness, in the first place? Is it really the case that an article, a course, or a women's group, holds the power to suddenly change our entire lives, seemingly without warning and without precedent? We have seen that the cultivation of a habit of flexibility and openness can enable us to reassess other habits, to doubt the certainty of previously taken-for-granted habits. Indeed, the concept of doubt is often posited by pragmatists as the basic prerequisite to inquiry, which in turn, can lead to change. On this account, doubt is conceived of as an "irritation," an underlying uncertainty that must be resolved. Thus, for Dewey (1997), doubt forms the very basis of thought: "The origin of thinking is some perplexity, confusion or doubt. Thinking is not a case of spontaneous combustion . . . There is something specific which occasions and evokes it. Given a difficulty, the next step is suggestion of some way out” (p. 12). One will naturally appeal to past experiences and previously accumulated knowledge to find the "way out," or the right course of action, in a given situation. However, if the problem is incapable of being answered by the already existing fund of prior knowledge, we must be open to further investigation.

As we know, Dewey believes that there is a tendency for us to rely on previous habits, including mental habits, and it is our rejection of this easy way out that truly enables critical thinking. For Dewey, 
the easiest way [out of perplexity] is to accept any suggestion that seems plausible and thereby bring to an end the condition of mental uneasiness. Reflective thinking is always more or less troublesome because it involves overcoming the inertia that inclines one to accept suggestions at their face value; it involves willingness to endure a condition of mental unrest and disturbance. Reflective thinking, in short, means judgment suspended during further inquiry; and suspense is likely to be somewhat painful . . . the most important fact in the training of good mental habits consists in acquiring the attitude of suspended conclusion ... To maintain the state of doubt and to carry on systematic and protracted inquiry - these are the essentials of thinking. (p. 13)

Dewey's positing of a self-reflexive, doubting habit that prompts questioning of other, entrenched habits (along with his account of doubt as the basis for reflective thought) highlights the link between change of the self and the development of new knowledge and new understanding of the changed self. This new knowledge emerges during transformative experiences and needs to be understood in terms of Dewey's naturalism, in which mind and nature are coterminous, and not separated realms. Hence, speaking of moral knowledge, Dewey (2002) asserts that "consciousness and conscience have more than a verbal connection" (p. 134). Moral knowledge is an organic function of moral situations and the self as responsible agent. ${ }^{16}$

I believe that this epistemological connection to selfhood is pertinent for an analysis of the process of coming to feminist consciousness, where new information and a reframing of previously taken-for-granted norms go hand in hand with the development of a new self. Thus, I maintain that the concept of doubt can be applied in this context, and used to explain the apparent abruptness and intensity of the conversion process. This is largely due to the fact that doubt can be protracted over extended periods of time, even covering the majority of one's life.

We can draw a parallel between the perplexity Dewey refers to as the initial catalyst for a process of inquiry and the confusion Segal relates in her experience as a woman prior to feminist consciousness. Her bewilderment and uncertainty associated with living in conflict with standard paradigms of femininity is something many women experience, as is acknowledged by her question: "Why were so many of us quite so confused?" The answer, of course, is that the ideals of femininity and masculinity endorsed by patriarchal societies are simply unattainable, hence, the confusion and perplexity caused by the contradiction of one's actual life and the ideal one is supposed to emulate. A feeling of confusion and an underlying suspicion that things just somehow do not fit right, a conscious or even subconscious feeling of doubt, is something that can infuse a person's life, even from a very young age. It is when we come to understand what it is we are to direct our doubt at, what we should be doubting, what is causing the contradiction in our lives, that we begin the process of coming to feminist consciousness. Otherwise, doubting remains a purely internalized suspicion, a feeling of unease, indeed, a self-doubt. ${ }^{17}$ Feminist analyses and a feminist interpretation of the world can help us understand what, exactly, is causing the unease Segal is referring to, and what is inducing these feelings of doubt that may have been with us for a lifetime. 
It is in this sense also that Sandra Bartky's (1990) depiction of feminist consciousness as an "anguished consciousness" (p. 14) is significant. Following Marx, Bartky similarly locates the possibility of change in contradictions, although not, as Dewey would, in contradictions of habit, but rather in "modes of production," as well as "in the social order" (pp. 13-14) more generally. For Bartky, such contradictions provide the very possibility of change, as they allow for a rejection of oppressive norms and for an imagining of a state of liberation. Bartky writes: "This possibility [of the liberation of women] is more than a mere accidental accompaniment of feminist consciousness; rather, feminist consciousness is the apprehension of that possibility" (p. 14). Beneath this identification of feminist consciousness as the apprehension of change lies an appreciation of the sense of indeterminacy involved in the process of raising said consciousness. Thus, "there is an anguished consciousness, an inner uncertainty and confusion which characterizes human subjectivity in periods of social change", hence "feminist consciousness, in large measure, is an anguished consciousness” (p. 14).

Bartky locates this uncertainty and confusion (reminiscent of Segal's account) in the actual conversion process itself, and in the subsequent negotiations of the self with a sexist world, which the feminist henceforth has to contend with. Rather than positing confusion and doubt as a precondition for raised consciousness, uncertainty results from the conversion process and characterizes one's existence as a feminist. ${ }^{18}$ While it is very likely that feminists experience feelings of uncertainty and doubt even after coming to feminist consciousness (particularly as they begin to reframe and reconceptualize the various aspects of their lives as "feminist"), Bartky's account perhaps places insufficient emphasis on the insights and certainty to be drawn from the social and communal nature of feminist consciousness as it is structured by means of the approval-disapproval mechanism. Additionally, not enough credence is given to doubt as a primary factor in initiating change. Although Bartky understands change as a consequence of contradictions, doubt appears during and after consciousness is raised. But isn't doubt a product of the contradictions required for change? And don't such contradictions occur (long) before the process of feminist consciousness is consciously embarked upon? By positing doubt as more or less dormant in selves - even over the course of extended periods of time-the radical feminist conversion experience can be re-evaluated.

Thus, in my own experience, I realize that my introduction to feminism amplified an already existing, nagging doubt, which had to be framed and trusted. This created a questioning of previously taken-for-granted, patriarchal explanations of the world, and led to further inquiry in the form of self-exploration and a search for new answers. In sum, the long-term presence of doubt induced by contradictory gender norms, combined with an introduction to feminist theory and feminist community ${ }^{19}$ and the resultant reassessment of self and environment, all constituted a monumental process of what Dewey terms "reflective thinking." Since the doubt underlying such critical thought was already present, and presumably growing before the actual feminist awakening as such occurred, we can see that coming to feminist consciousness is not as sudden as it may initially seem, but rather a protracted process that has its root in the very contradictions making up our selves. Dewey's account of heightened tension created by clashing habits as a catalyst for change gives further credence to this. The feminist depiction of coming to feminist consciousness as an "aha moment" or a conversion can thus be replaced by a more 
gradual account of this transformative process. Doubt and uncertainty experienced over a prolonged period of time before raised consciousness give way to greater clarity and assuredness once the reorganization of habits begins to take place. While perplexity will presumably persist to some extent, the tension of conflicting habits will ease off as the self comes to reconstitute itself in light of feminist consciousness.

We have seen, then, that Dewey's view of the changing self provides a framework for understanding the gradual process involved in coming to feminist consciousness: a coherent self undergoes substantial change by dropping habits or changing them in favour of new ones. These new habits are acquired by means of the approvaldisapproval mechanism, with a new, feminist group now informing one's habits. While doubt lies at the very root of change, we have also seen that this can linger in a woman's conscious or unconscious life for a very long time, making the conversion process all the more intense as it covers a whole plethora of habits acquired over the course of a lifetime. This change in the self is epistemically conditioned, as new knowledge and a new understanding of self and world are integral to the transformation experienced in the process of coming to feminist consciousness. Finally, the movement of growth, the movement toward a "better" self, is presumed by Dewey in all of this. With this model of change and progress I want to return to the possibility of wider, systemic change touched upon earlier.

\section{Beyond the Self}

Dewey's thought is fundamentally melioristic: his belief in the betterment of our selves and our world is constantly present in his writing on politics, economics, and a myriad of other topics. Growth, for Dewey, is a moral category: an evolving self has the agency to choose to improve, that is, to choose a new self over an old self, indeed, a good self over a bad self. Where this becomes problematic, of course, is when it comes to defining what is good and what is bad. Who gets to decide what constitutes progress? ${ }^{20}$ While this may be seen as a stumbling block, I believe that it is possible to use Dewey's insights on change examined above, to counter some of the more problematic aspects of "change as progress." An in-depth discussion lies beyond the scope of this essay. I will, however, make the following suggestion: Dewey's radical and passionate attachment to democracy can provide a useful tool for further analysis, including allowing for a democratically devised notion of progress, indeed a multiplicity of accounts of progress. Dewey's view of democracy as a system involving collective inquiry has already been described as a precursor to what is now known as deliberative democracy. This holistic and cooperative approach could be strengthened by the model of inclusive democracy outlined by Iris Marion Young (2000) in Inclusion and Democracy. Such a model could allow for progress to be expressed and heard by all members of society, including those on the margins. Inclusion is particularly pertinent from a feminist point of view, as women's traditional exclusion from spheres of power has resulted in oppressive institutions and systems that are especially harsh on women and girls.

In light of this, we should be mindful of the connection between changes in selves and larger systemic changes. I have argued that the latter can come about through the instantiation of the former. While feminist theorists have long drawn attention to the 
importance of a changed self as a precondition for more wide-spread and institutional change, I believe that a feminist-pragmatist understanding of the habituated self can illuminate how the self functions in oppressive systems, and the role it plays in sustaining and upholding such systems. Feminist analyses are capable of shedding light on the specifically gendered nature of our beings (whether conscious or unconscious), while Dewey's explication of the self as a fund of habits allows for structure and flexibility in its depiction of an enduring-yet-dynamic self. By adopting this feminist-pragmatist view of a morally responsible self capable of change, indeed responsible for change, social movements can gain a clearer picture of the moral self, and the potential it holds to effect broader systemic change. Dewey's notion of progress, when rearticulated as an expression of inclusive or deliberative democracy, can help us to evaluate the changes we seek to realize. I noted in the introduction to this essay that social movements often fail to bring about the changes they promise. I maintain that a feminist-pragmatist understanding of change, as proffered above, can aid the production of systemic change by being an effective instrument in the understanding and dismantling of oppressive norms and systems, thereby fulfilling social movements' aspirations for social justice.

\section{Conclusion}

In this essay, I have argued for a feminist-pragmatist analysis of change. Such an analysis allows us to theorize oppressors and oppressed as instigators and participants in transformative processes. At the level of the self, we saw how this is possible by applying a feminist-pragmatist analysis to the process of coming to feminist consciousness. By combining Dewey's view of a habituated dynamic-yetstable self with feminist analyses of sexism and feminist consciousness, we arrive at a notion of selfhood that can support the self's diminishment of unconscious sexist habits. This feminist-pragmatist view of selfhood is also fundamentally connected to epistemological concerns, as we can draw parallels between the process of coming to feminist consciousness and Dewey's notion of "reflective thinking." We should also note the centrality of doubt and self-reflexivity in bringing about change, and the importance of group approval/disapproval in the creation of new habits. Finally, I have argued that a feminist-pragmatist analysis of change is also applicable on a wider, systemic scale, with Dewey's promotion of democracy harbouring the potential for a rethinking of the notion of progress itself. In sum, we can say that a feminist-pragmatist interpretation of change overcomes the determinismresponsibility problem by restoring agency and moral responsibility to individuals, thereby facilitating personal and social change. Thus, change becomes a moral process capable of undermining oppressive systems, while holding the promise of a continuous and truly radical transformation of our lives, in the realization of social justice. Rethinking social justice as a matter concerning not only political institutions and structures, but also personal transformation and consciousness, enables us to counter what Bartky calls the "half-submerged weapons" of sexism with a greater understanding of the unconscious habits of the feminist-pragmatist self. 


\section{Clara Fischer}

\section{Notes}

1 I wish to thank all those who generously shared their thoughts on this paper, especially the anonymous reviewer and the editors of this volume, Phyllis Rooney and Catherine Hundleby.

2 Ferguson writes: “According to this theory, the human agent instrumentally adopts gender norms and identities because of rewards or punishments received for doing so. Women accept less pay for equal work and do more unpaid work in the family than men do, not because we are more altruistic than competitive or self-interested, but simply because the external and social constraints against not doing this create more costs than benefits" (1997, p. 120).

3 Both pragmatism and feminism critique the widely held philosophical view of the self as abstract and disconnected. Hence, corporeality and the social nature of our existence are not simply theorized away, but are shown to be fundamental aspects of the way we experience our selves, each other, and our environment. To this end, feminist and pragmatist theorists have highlighted the arbitrariness of philosophical dualisms which set up aspects of our lives in opposition to each other, with the second oppositional usually assuming an inferior role. Mind/body, individual/community, subject/object-all of these dualisms constitute a false and unnatural separation of coterminous spheres, and as feminists have shown, the identification of women with all of these allegedly subordinate secondary categories has played a vital role in the perpetuation and justification of patriarchal norms. For more on the overlap between feminist and pragmatist critiques of dualisms, see particularly chapter seven of Seigfried's Pragmatism and Feminism: Reweaving the Social Fabric (1996).

4 For Dewey, these are usually actions, however, he notes that this does not imply a disconnectedness of individual acts or of acts from the self, but rather, "habit covers in other words the very make-up of desire, intent, choice, disposition which gives an act its voluntary quality. And this aspect of habit is much more important than that which is suggested merely by the tendency to repeated outer action, for the significance of the latter lies in the permanence of the personal disposition which is the real cause of the outer acts and of their resemblance to one another. Acts are not linked up together to form conduct in and of themselves, but because of their common relations to an enduring and single condition - the self or character as the abiding unity in which different acts leave their lasting traces" (Dewey, 1985a, p. 171).

5 This essay will only deal with certain aspects of Dewey's ethical thought. For a more detailed account of Dewey's ethics see Welchman (1995), Fesmire (2003) or most recently Pappas (2008).

${ }^{6}$ At the risk of seeming narcissistic, this essay makes use of my own experiences, a move that is not supposed to put my life in the forefront, but rather to ground the larger, theoretical concepts under discussion, in the particular. This emphasis on contextualism is typical of much pragmatist and feminist theorizing, where the traditional philosophical view-fromnowhere is replaced by a view-from-here. For more on this see Paula Droege (2002).

7 Dewey (1985a) expresses this as follows: "We set up this and that end to be reached, but the end is growth itself. To make an end a final goal is but to arrest growth. Many a person gets morally discouraged because he has not attained the object upon which he set his resolution, but in fact his moral status is determined by his movement in that direction, not by his possession” (p. 306).

8 This is not to imply that those who experience extreme victimization in oppressive systems have the same capacity or power as their oppressors to change those systems. However, a complete denial of agency simply replicates the dehumanizing portrayal of the oppressed by the oppressors. Also, as social constructionists have shown, the deep-seated psychological impact of life in an oppressive system can blind us to certain internalized, sexist norms, which in turn would have an impact on agency and moral responsibility. As noted, this should not infer a lapsing into overly deterministic models of social construction which cannot be escaped, but should spur a reassessment of how the Deweyan model of selfhood can accommodate the unconscious. This will be explored in the next section.

9 Rebecca Klatch (2001) similarly outlines the process of coming to feminist consciousness experienced by Sue Jhirad, who was active in the U.S. left-wing organization, Students for a Democratic Society (SDS): 
"I just had this complete and total revelation that suddenly everything was sort of turning inside out . . . I began to see all these things that happened to me in my life . . . I began to see for the first time ... these were political questions. I got very engaged in the women's movement at that point” (p. 808).

10 See, for example, Alcoff (2003).

11 Bartky (1990) describes this elusiveness as follows: "It is difficult to characterize the tone of an article, the patronizing implications of a remark, the ramifications of some accepted practice, and it is even more difficult to describe what it is like to be bombarded ten or a hundred times daily with these only half-submerged weapons of a sexist system” (p. 17).

${ }^{12}$ Feeling part of a new group, and the attendant experience of solidarity, is also something Erika Summers-Effler (2002) holds to be an integral part of the experience of feminist consciousness.

13 This is not to assert that there is only one feminist community, or that feminists do not hold different and often opposed views on how to overcome the difficulties posed by patriarchy. However, as feminism is often treated as a uniform discourse by those who find themselves outside of this discourse, for many women coming to feminist consciousness, the types of feminisms and the various strategies proposed by feminists remain to be seen. What is important in the process of feminist "enlightenment," however, is not an immediate understanding of the multiplicity and complexity of feminism, but rather that there is an alternative to the norms professed by patriarchy. That there are in fact many alternatives, is something which only gradually transpires the more one learns about feminism as such.

${ }^{14}$ This approach of supplementing Dewey's thought with feminist analyses of the ubiquity of sexist norms is also something Erin McKenna (2002) advocates. Shannon Sullivan (2004) similarly explores the difficulty of challenging unconscious oppressive habits. She writes: "a pragmatist understanding of habit . . . needs development in connection with a psychoanalytic appreciation of fantasy, desire, and pleasure and a psychoanalytic picture of the unconscious as often actively scheming against one's best efforts at change” (p. 200).

${ }^{15}$ Which, as I have noted is not uniform, but actually consists of a whole variety of different groupings with differing beliefs and political approaches.

${ }^{16}$ In this essay I have used the phrase "coming to feminist consciousness" in the sense of awakening, awareness, etc. as it is typically used by feminists. Dewey's use of the word "consciousness" here should be understood in broad, epistemological terms as "a special agent for knowledge," be it "soul, consciousness, intellect or a knower in general” (p. 184). As I have noted above, a separate, "special agent for knowledge," which is detached from experience and nature is something Dewey strongly criticizes.

${ }^{17}$ Feminists have frequently pointed out that such self-doubting can lead to serious mental and physical health problems. Betty Friedan (1965), for example, outlined the lived contradictions and resultant anxiety experienced by middle class suburban North American women, and highlighted the increase in alcoholism among such women. One need also merely think of the myriad of women suffering from eating-disorders and negative bodyimage to see how self-doubt, induced by contradictions in patriarchal ideals of femininity and women's lived experiences, negatively affects women.

18 Bartky notes that "it might be objected that the feature of feminist experience I have been describing is characteristic not of a fully emergent feminist consciousness but of periods of transition to such consciousness, that the feminist is a person who has chosen her moral paradigm and who no longer suffers the inner conflicts of those in ambiguous moral predicaments. I would deny this. Even the woman who has decided to be this new person and not that old one, can be tormented by recurring doubts. Moreover, the pain inflicted in the course of finding one's way out of an existential impasse, one continues to inflict” (p. 20).

${ }^{19}$ Recourse to the extensive work carried out by previous generations of feminists is something that plays an instrumental role in the process of coming to feminist consciousness. The fact that there is an existing language through which gender norms can be named and analyzed, means that the groundwork for a feminist reframing, so to speak, has already been laid, allowing younger women to join an already well-established feminist discourse. Klatch (2001) notes the limitations women experienced in absence of such discourse: "Early SDS women did not have access to a vocabulary to voice grievances. The prevailing universe of political discourse excluded women's experiences from the pool of legitimate grievances; they were viewed as personal or diversionary from the real political issues. There was no 


\section{Clara Fischer}

prevailing language by which to frame discontent . . . Without a language to label their experiences, these individual feelings were not recognized as being rooted in gender nor were they seen as collective issues” (pp. 803-804).

${ }^{20}$ This question is also akin to "what about change for the worse?" So far we have seen that Dewey assumes growth to be a movement toward the better, i.e. progress. But is it not also true that people, systems, and institutions often change for the worse? Dewey's organic view of the world seems to imply that a person changing for the worse is actually a person clinging to old habits, becoming dogmatic and therefore not changing as she should in accordance with the changes happening around her. Thus, the damage is done by stasis instead of change, as progress is prohibited. However, as the above section argues, "change for the worse" can perhaps best be elucidated by clarifying how characterizations such as worse, better, and progress are defined and by whom.

\section{References}

Alcoff, L. M. (Ed.). (2003). Singing in the fire: Stories of women in philosophy. Lanham, MD: Rowman \& Littlefield.

Bartky, S. L. (1990). Toward a phenomenology of feminist consciousness. In Femininity and domination: Studies in the phenomenology of oppression (pp. 11-21). London: Routledge.

Dewey, J. (1985a). Ethics. In J. A. Boydston (Ed.), John Dewey: The later works, 1925-1953, Vol. 7: 1932. Carbondale \& Edwardsville, IL: Southern Illinois University Press.

Dewey, J. (1985b). The public and its problems. In J. A. Boydston (Ed.), John Dewey: The later works, 1925 - 1953, Vol. 2: 1925-1927. Carbondale \& Edwardsville, IL: Southern Illinois University Press.

Dewey, J. (1988). Experience and nature. In J. A. Boydston (Ed.), John Dewey: The later works, 19251953, Vol. 1: 1925. Carbondale \& Edwardsville, IL: Southern Illinois University Press.

Dewey, J. (1997). How we think. Mineola, NY: Dover Publications.

Dewey, J. (2002). Human nature and conduct. Mineola, NY: Dover Publications.

Droege, P. (2002). Reclaiming the subject, or a view from here. In C. H. Seigfried (Ed.), Feminist interpretations of John Dewey (pp. 160-185). University Park, PA: The Pennsylvania State University Press.

Ferguson, A. (1997, Summer). Moral responsibility and social change: A new theory of self. Hypatia, 1(3), 116-142.

Fesmire, S. (2003). John Dewey and moral imagination: Pragmatism in ethics. Bloomington \& Indianapolis, IN: Indiana University Press.

Friedan, B. (1965). The feminine mystique. London, UK: Penguin.

Gouinlock, J. (1972). John Dewey’s philosophy of value. New York, NY: Humanities Press.

Klatch, R. (2001, December). The formation of feminist consciousness among left- and right-wing activists of the 1960s. Gender \& Society, 15(6), 791-815.

Pappas, G. F. (2008). John Dewey's ethics: Democracy as experience. Bloomington \& Indianapolis, IN: Indiana University Press.

McKenna, E. (2002).The need for a pragmatist feminist self. In C. H. Seigfried (Ed.), Feminist interpretations of John Dewey (pp. 133-159). University Park, PA: The Pennsylvania State University Press.

Segal, L. (2007). Making trouble: Life and politics. London: Serpent's Tail.

Seigfried, C. H. (1996). Pragmatism and feminism: Reweaving the social fabric. Chicago, IL: The University of Chicago Press.

Seigfried, C. H. (Ed.). (2002). Feminist interpretations of John Dewey. University Park, PA: The Pennsylvania State University Press.

Sullivan, S. (2000, Winter). Reconfiguring gender with John Dewey: Habit, bodies, and cultural change. Hypatia, 15(1), 23-42.

Sullivan, S. (2004). From the foreign to the familiar: Confronting Dewey confronting racial prejudice. Journal of Speculative Philosophy, 18(3), 193-202.

Summers-Effler, E. (2002, March). The micro potential for social change: Emotion, consciousness, and social movement formation. Sociological Theory, 20(1), 41-60. 
Welchman, J. (1995). Dewey’s ethical thought. London, UK: Cornell University Press.

Young, I. M. (2000). Inclusion and democracy. Oxford, UK: Oxford University Press. 